\title{
Metal Coated Coir Fiber for Smart Textile Applications
}

\author{
Melvi Chandy ${ }^{1}$, M. S. Latha², K. Shreekrishna Kumar³ , U. S. Sarma ${ }^{4 *}$
}

\begin{abstract}
Thermo regulated textiles attracted attention in cold countries for outdoor activities in extreme winter conditions. Temperature regulation of textiles for use in adverse environmental condition can be achieved by integrating heat regulated natural fibers into textile construction. Coir being an abundantly available, cheap and biodegradable natural fiber seems to be a material worthy of investigation. Light weight and insulation of coir fiber add to the comfort of the wearer in textile application.

In this study, coir surface is made conductive by metal coating and temperature regulation is achieved by applying a small voltage. Copper, aluminium and silver metals are used for coating the coir fiber surface. Thin film coating on one side of coir fiber is done by vacuum deposition technique. Temperature regulation of upto 12 degrees is found to be possible by the application of a potential of about 1 Volt. Analysis of variance is used to compare the effect of thickness of coating and type of coating material on heat production with respect to voltage. Metal coating on coir fiber is found to provide a versatile combination of physical, thermal and optical properties and can be subjected to textile processing without any problem for the development of smart textiles.
\end{abstract}

Keywords: metals, vacuum deposition, smart textiles, analysis of variance, coir fibers

\footnotetext{
${ }^{1,3}$ School of Technology and Applied Sciences, Mahatma Gandhi University, Malloossery Post Office, Kottayam District, Kerala-686 041, India,

${ }^{2}$ S. N. College, Neduvaramcode P. O., Alappuzha District, Kerala-689 508, India,

${ }^{4}$ Central Coir Research Institute, Kalavoor Post Office, Alleppey District, Kerala-688522, India,

*To whom correspondence should be addressed. E-mail: uss_2000@yahoo.com
} 


\section{Introduction}

Coir fibers are obtained from coconut husk by the process of retting or mechanical combing. Traditionally coir fibers are widely used for making yarn, mats and matting. Nowadays, these products are facing stiff competition from synthetic substitutes in the domestic and export market. Since a large quantity of coir fiber is produced from India, it is necessary to make use of coir fibers for new diversified purposes.

Coir fiber is resistant to water logging and is an insulating material due to the presence of air pockets in the microscopic holes on the surface. It is lignocellulosic in nature and the high lignin content of about $45 \%$ makes it resistant to damage by salt water (Stern 1957). Coir fibers have specific mechanical properties and also additional advantages of environment friendliness, low cost, renewable, and biodegradable properties (Bledzki and Gassan, 1999; Cho et al., 2001; Joffe et al., 2003). Because of its superior properties over other natural fibers, it can be used widely for making products useful for industrial applications and day today life.

Figure 1. Coir fibers and Coir yarn

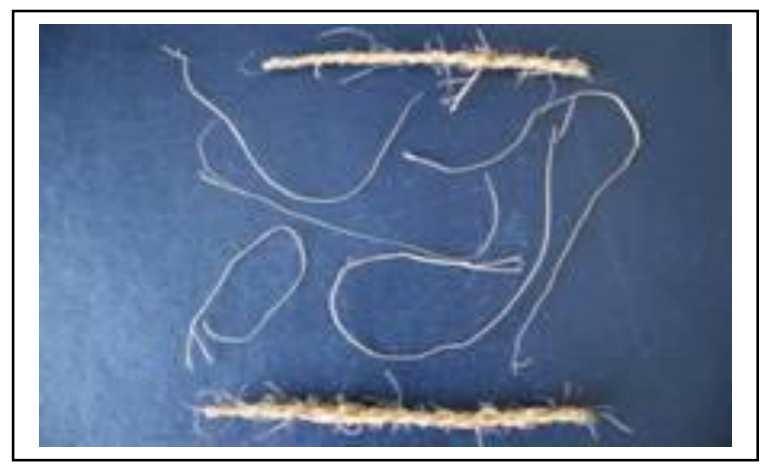

Many different techniques for modifying coir fibers to enhance its aesthetics or improve its performance have been developed over the last several decades. Methods for coating large areas of substrates currently include wet chemical, thermal evaporation and magnetron sputtering and potential technologies include plasma assisted CVD, electro deposition and ion beam techniques. The technology of vacuum deposition has seen great progress in recent years (Yao et al.
1993). Here an effort is made to explore the possibility of enhancing the property of coir fiber by surface coating using thermal evaporation techniques. The thin film metal coating of coir fibers would open up the possibility of usage of coir fibers in large scale.

\section{Objective}

Coir is obtained from the waste product namely, husk, after extracting the nut from the coconut fruit. It is the cheapest but strongest natural fibre and is easily available. The ease of surface modification and metal coating, make it an attractive material for the development of thermo regulated textiles. However, there is no report on the use of coir in this area. The objective of this work is to investigate the potential of using coir fiber as a material for the development of temperature regulated textiles.

Coir fiber is an insulator and metal coating on selected surface of the fiber is found to increase the surface conductivity. This provides a method for achieving temperature regulation by applying a small voltage. Application of about $1 \mathrm{~V}$ potential is found to increase the temperature by about 12 degrees. This study demonstrates the feasibility of using metal coated coir fiber for the development of smart textiles with temperature regulation.

The effect of thickness of coating and the type of coating material on heat production with respect to voltage is quantified by using Analysis of Variance. This study demonstrates the feasibility of using metal coated coir fiber for the development of smart textiles with temperature regulation.

\section{Materials and methods}

\section{Preparation of Metal Coated Coir Fiber}

Thin films of Silver, Aluminium and Copper metals were vapor deposited by the vacuum deposition method in a conventional diffusion pumped vacuum system into coir substrates held at room temperature. The pressure before evaporation is kept at $2^{*} 10^{-6}$ Torr and then it is increased to about $7 * 10^{-6}$ Torr during evaporation. The deposition rate was 


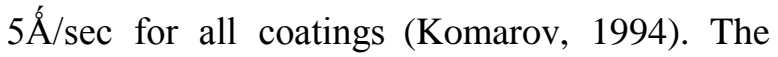
thickness of the coating was monitored by using a quartz crystal monitor. Since the size and shape of the coir fibers may vary from fiber to fiber, we had taken a set of 20 samples to produce a reliable result. Nine sets of films were deposited using thermal evaporation with different coating materials such as Silver, Copper and Aluminium at various thicknesses of $200 \AA \AA, 500 \AA ̊$ and $1000 \AA$, to have a comparative study.

\section{Heat Regulation of Coated Fiber}

The electrical characterizations of these deposited thin films are done by using Keithley Source Meter Model-2400. Heat measurements on the uncoated side of the coir fibers were carried out using Platinum Resistance Thermometer Model-100 [PT-100] (Barber, 1955). For studying the heating effect of electric current through these fibers a DC current was passed through the conducting portion of the fiber and measured the temperature created on the uncoated side of the coir fiber using PT-100. The schematic diagram of the experimental setup is shown in Figure 2. Potential difference across the electrodes was varied from $0.1 \mathrm{~V}$ to $1.0 \mathrm{~V}$ in steps of $100 \mathrm{mV}$. For studying the effect of time on heating, a potential difference of $1 \mathrm{~V}$ was applied across the electrodes and the temperature was monitored at intervals of 1 minute, for 5 hours.

Figure 2. Experimental Setup

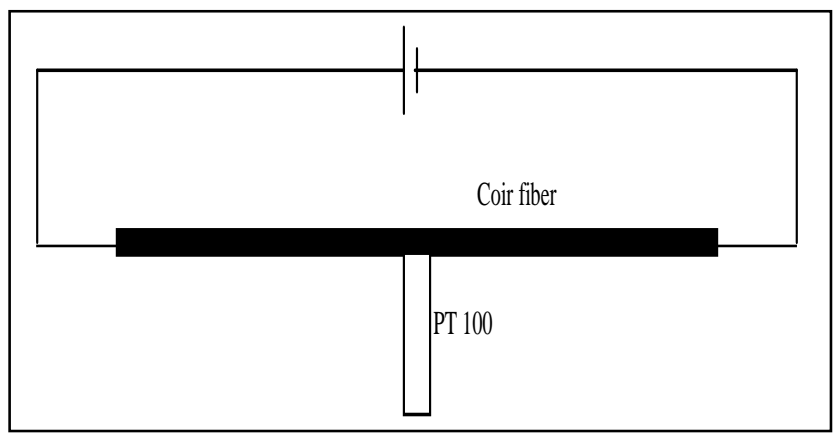

\section{Stability of Metal Coated Coir Fiber}

Temperature stability for deposited coir fibers were studied by annealing the samples at $70^{\circ} \mathrm{C}, 80^{\circ} \mathrm{C}, 100^{\circ} \mathrm{C}, 125^{\circ} \mathrm{C}, 150^{\circ} \mathrm{C}$ and $200^{\circ} \mathrm{C}$, for 30 minutes and visually examined the stability.

\section{Results and discussions}

Development of a wearable thermo regulated textile involves the use of material which would provide optimum warmth without compromising comfort of the wearer, appearance and durability of the clothing. Phase Change Materials attained considerable attention in this area and a few products are commercially available now (Czajka 2005, Linti 2006). Unlike other insulating materials Phase Change Materials work interactively with body temperature. It can absorb heat due to fusion when heat is generated in the body during physical activities and release heat on cold exposition. Metal alloys have also been investigated for the development of temperature regulated textile applications. Nickel-titanium and Cuprous-zinc alloys are studied for the purpose. Compatibility with textile is a major limitation with these alloys. Polymeric materials like styrene- butadiene- polyethylene Terephtalate - Polyetylene OxydePolyurethane - Polycaprolactone -etc were also been investigated in this area.

Over the last decade development of temperature regulated fabric probe into battery powered textiles. Here heat generation can be controlled externally. High wicking finishes with a high content of nickel, copper, silver or carbon was reported to provide electrical or thermal conductive fabrics. Direct use of conductive yarns of metals or conductive polymer was also found to produce conductive fabrics. Efforts are being made to improve temperature regulation, expense and wearability of these fabrics (Dietzel et al., 2000).

In this study we used cheap and abundantly available coir fiber for the development of thermo regulated textiles. Coir is a natural fiber and has been investigated much for versatile applications. Being a biodegradable cellulosic fiber with nontoxic degradation products coir fiber poses no environmental pollution. 
Figure 3 shows the SEM of uncoated and thin film coated Coir fiber. The surface of uncoated coir fiber shows the presence of micro pores. Metal coated fiber, on the other hand is smooth and without any pores indicating the formation of metal layer on the surface. Micro environment of skin and garment is of prime importance in keeping the body warm. Porous environment of the garment reduce heat loss from body and keep the body warm. Air pockets in the micro pores of uncoated coir make it an insulator and are advantageous in textile application as it supplements the boundary layer or air gap on the surface of the skin. Here, only one side of the fiber is coated with metal so that the surface facing the skin of the wearer remains as such providing enough comfort. Smooth coating is achieved by vacuum deposition of metal on the other side of the fiber, which is necessary for producing uniform heating on the application of potential difference. Morphological analysis revealed the formation of smooth metal coating on one side of the fiber while it remains porous on the uncoated side. There is not much difference on the surface properties of the fiber with the nature of metal used for coating. Silver, Aluminium and Copper coated fiber shows similar surface characteristics.

Figure 3. SEM micrographs of the fiber surfaces (a) raw (b) $200 \AA$ Copper (c) $500 \AA$ Á Silver (d) 500Á Aluminium (e) $500 \AA ̊$ Copper (f) $1000 \AA ̊$ Silver (g) $1000 \AA ̊ A l$ Aluminium (h) $1000 \AA ̊$ Copper

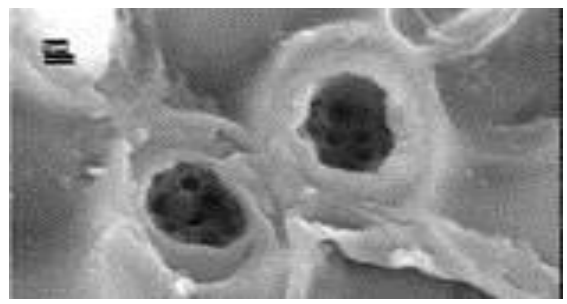

(a)

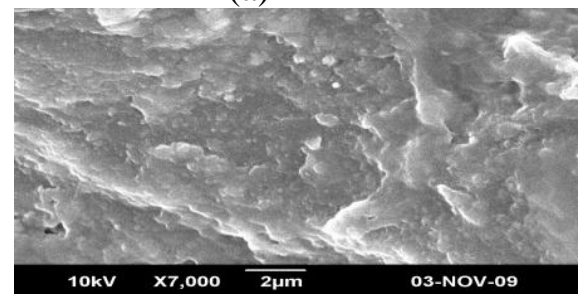

(b)

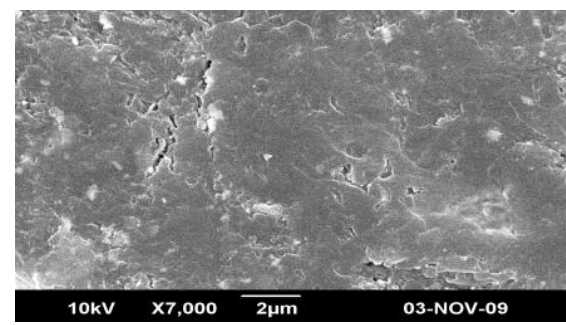

(c)

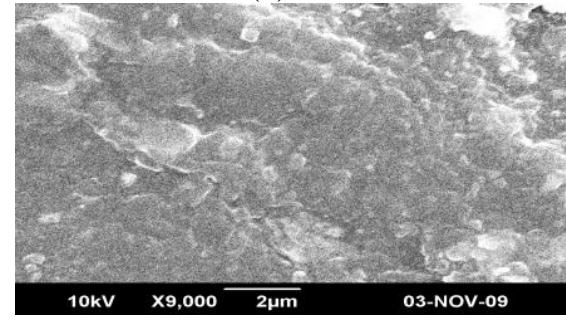

(d)

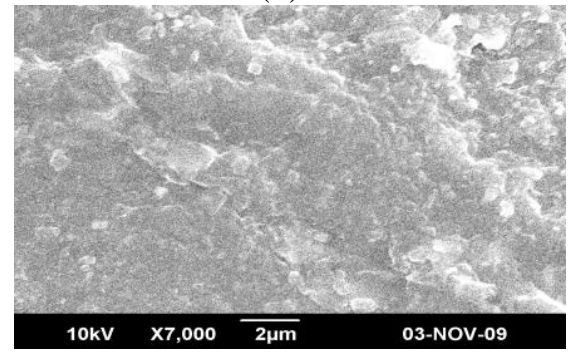

(e)

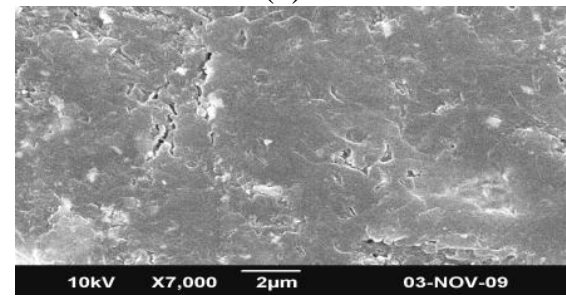

(f)

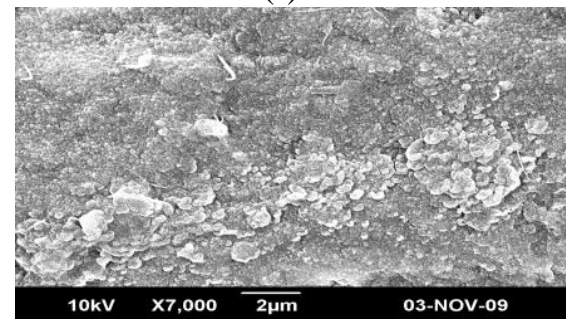

(g)

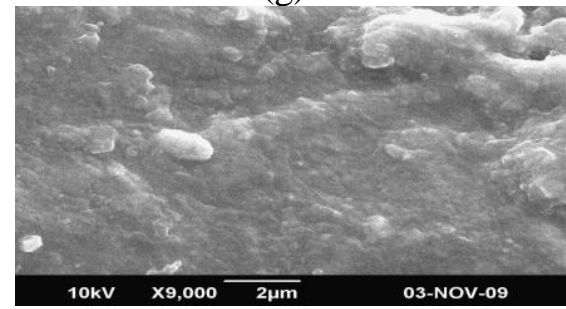

(h) 
Virgin coir fiber is found to be a perfect insulator and does not produce any heating effect under applied potential. Effect of potential difference on the temperature increase of coir fiber coated with Silver, Aluminium and Copper is shown in Table 1. All the samples studied produced a heating effect by the application of potential difference and there is not much difference in the heating effect produced with the metal used for coating under the conditions studied. This shows that the conductivity of the coated surface is independent of the type of metal used for coating. A potential difference of one Volt is found to increase the temperature of 200 Á silver coated fiber by 12 degrees at the uncoated side of the coir fiber, at $30^{\circ} \mathrm{C}$. Maximum heating effect is produced in one minute. Coating thickness of $200 \AA \hat{L}, 500 \AA \hat{\text { and }}$ $1000 \AA$ is used in the present study. Temperature rise on application of electric potential is found to be maximum for coir fiber with coating thickness of $200 \AA$. The rise in temperature is found to decrease with thickness of the coating. This can be attributed to the decrease in electric resistance with thickness of the film. Metal coating allows the passage of electricity on the surface of coir and as per Joules Heating effect; heat is produced in the fiber. Analysis of Variance is used to find the effect of thickness of coating and type of coating material on the temperature produced with respect to voltage (Levin Richard I., Rubin David S., 1994). According to Analysis of Variance the larger value $\mathrm{F}$ ratio, calculated by computing the ratio of first estimate of the sample variance based on the variance among the sample means and the second estimate of the sample variance based on the variances within the samples, implies that a difference does exist in the effects of thickness of coating and the coating material on temperature produced. The nearer the $\mathrm{F}$ ratio comes to 1 , and then the more it is inclined to accept the independence of thickness of coating and material used for coating on temperature produced. The first estimate of the sample variance is given by the relation:

$$
\mu^{2}=\Sigma n_{j}\left(x_{j}-y\right)^{2} / k-1
$$

where $\mu^{2}$ is the first estimate of the sample variance based on the variance among the sample means. $n_{j}$ is the size of the $j$ th sample, $x_{j}$ is the temperature mean of the $\mathrm{j}$ th sample, $\mathrm{y}$ is the grand temperature mean and $\mathrm{k}$ is the number of samples.

The second estimate of the sample variance is given by the following relation:

$$
\mu^{2}=\Sigma\left(\mathrm{n}_{\mathrm{j}}-1\right) / \Sigma\left(\mathrm{n}_{\mathrm{T}}-\mathrm{k}\right) \mathrm{s}_{\mathrm{j}}^{2}
$$

where $\mu^{2}$ is the second estimate of the sample variance based on the variances within the samples, $n_{j}$ is the size of the $j$ th sample, $s_{j}^{2}$ is the sample variance of the $\mathrm{j}$ th sample, $\mathrm{k}$ is the number of samples and $\mathrm{n}_{\mathrm{T}}$ is the total sample size.

For Silver, Aluminum and Copper coated samples at thicknesses $200 \AA, 500 \AA$ and $1000 \AA$, the value of $F$ ratio ranges from 1.51005 to 25 , for given voltages. This larger $F$ value corresponds to the dependence on the temperature produced on the thickness of coating.

The $\mathrm{F}$ ratio when calculated among samples of different coating materials for same thickness ranges from .908 to 1.This can be explained by the fact that the temperature production is independent of the material used for coating.

Variation of temperature with applied voltage is shown in Figure 3. Initially there is a gradual increase in temperature with increase of potential and maximum effect is produced at 1 Volt. Further enhancement up to 5 Volt does not show any appreciable change in temperature. Table 2 shows the effect of time on temperature produced. Maximum temperature is obtained in one minute and thereafter the temperature remained the same with change in time up to 300 minutes. Figure 4 depicts the variation of temperature on uncoated side of the coir fiber with time. All the metals show the same effect.

Flexibility of the fiber is important in textile processing. Coir fiber is found to be very sensitive to temperature. At room temperature coir fiber is golden in colour and flexible in nature. The fiber remains flexible with golden colour upto $80^{\circ} \mathrm{C}$. As the temperature is increased further, color of coir fiber is found to 
Table 1. Temperature variation on uncoated side of the coir fiber with the applied voltage

\begin{tabular}{|c|c|c|c|c|c|c|c|c|c|}
\hline \multirow{2}{*}{$\begin{array}{c}\text { Voltage } \\
\text { (volts) }\end{array}$} & \multicolumn{3}{|c|}{$\begin{array}{c}\text { Temperature }\left({ }^{\circ} \mathrm{C}\right) \\
\text { Silver }\end{array}$} & \multicolumn{3}{c|}{$\begin{array}{c}\text { Temperature }\left({ }^{\circ} \mathrm{C}\right) \\
\text { Copper }\end{array}$} & \multicolumn{3}{c|}{$\begin{array}{c}\text { Temperature }\left({ }^{\circ} \mathrm{C}\right) \\
\text { Aluminium }\end{array}$} \\
\cline { 2 - 10 } & $200 \AA$ & $500 \AA$ & $1000 \AA$ & $200 \AA$ & $500 \AA$ & $1000 \AA$ & $200 \AA$ & $500 \AA$ & $1000 \AA$ \\
0.0 & 30 & 30 & 30 & 30 & 30 & 30 & 30 & 30 & 30 \\
0.1 & 30 & 30 & 30 & 30 & 30 & 30 & 30 & 30 & 30 \\
0.2 & 31 & 31 & 32 & 31 & 31 & 31 & 31 & 31 & 32 \\
0.3 & 33 & 32 & 33 & 33 & 32 & 32 & 33 & 32 & 33 \\
0.4 & 34 & 32 & 33 & 34 & 32 & 33 & 34 & 32 & 33 \\
0.5 & 35 & 32 & 34 & 35 & 32 & 33 & 35 & 32 & 33 \\
0.6 & 38 & 34 & 34 & 38 & 34 & 34 & 38 & 34 & 34 \\
0.7 & 39 & 35 & 34 & 39 & 35 & 34 & 39 & 35 & 34 \\
0.8 & 41 & 35 & 35 & 41 & 35 & 34 & 41 & 35 & 35 \\
0.9 & 42 & 36 & 35 & 41 & 35 & 34 & 41 & 36 & 35 \\
1.0 & 42 & 36 & 34 & 41 & 35 & 34 & 41 & 36 & 35 \\
\hline
\end{tabular}

Table 2. Temperature variation on uncoated side of the $200 \AA$ coated coir fiber with time

\begin{tabular}{|c|c|c|c|}
\hline \multirow{2}{*}{$\begin{array}{c}\text { Time } \\
(\text { Min })\end{array}$} & \multicolumn{3}{|c|}{ Temperature $\left({ }^{\circ} \mathrm{C}\right)$} \\
\cline { 2 - 4 } & Silver & Copper & Aluminium \\
\hline 1 & 42 & 41 & 41 \\
2 & 42 & 41 & 41 \\
3 & 42 & 41 & 41 \\
& $\cdot$ & 41 & 41 \\
& $\cdot$ & 41 & 41 \\
& 42 & $\cdot$ & $\cdot$ \\
& $\cdot$ & $\cdot$ & $\cdot$ \\
& 42 & $\cdot$ & 41 \\
& & $\cdot$ & $\cdot$ \\
& & 41 & 41 \\
\hline
\end{tabular}


Figure 4. Temperature variation on uncoated side of the coir fiber with Voltage (a) Silver (b) Copper (c) Aluminium at the coating thickness of $200 \AA, 500 \AA$ and $1000 \AA$

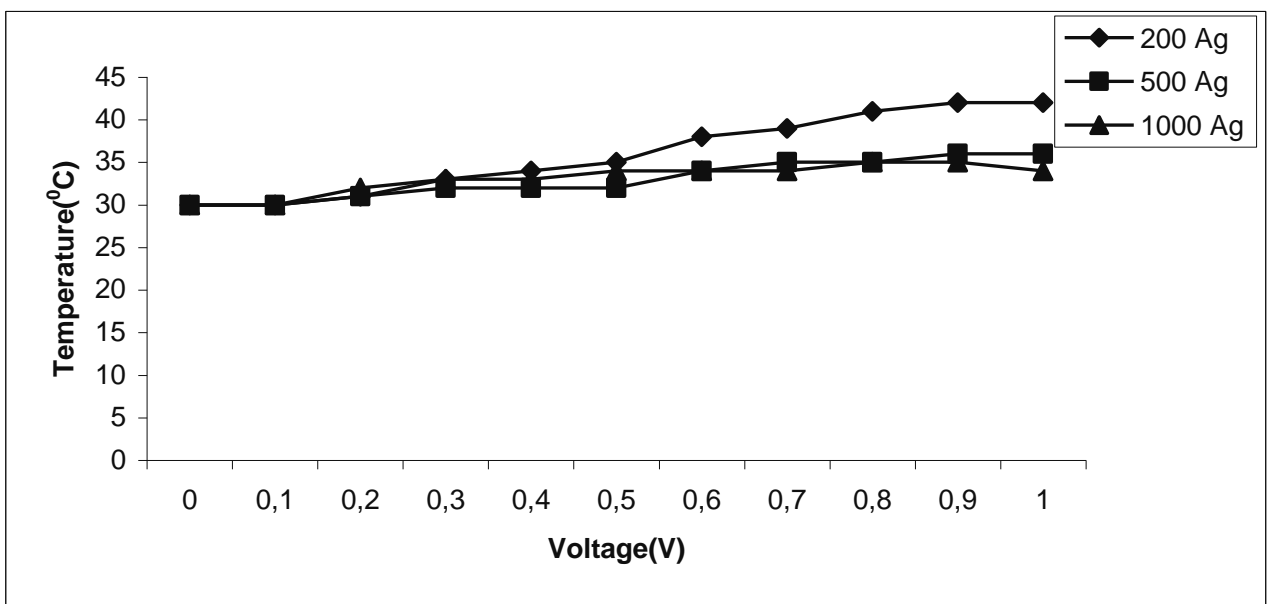

(a)

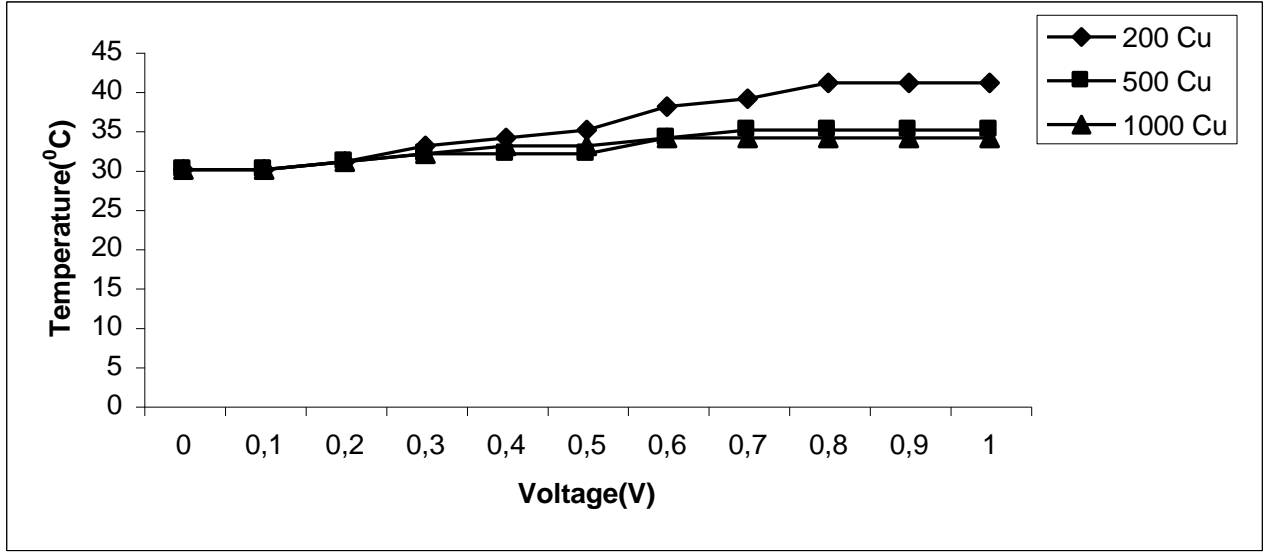

(b)

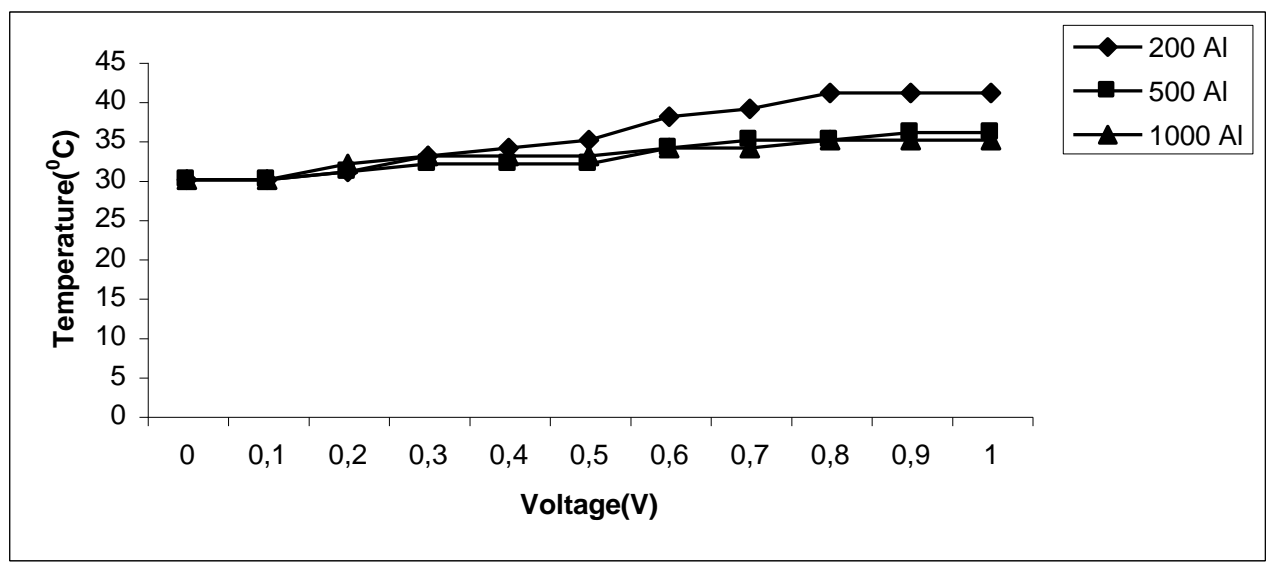

(c) 
Figure 5. Temperature variation on uncoated side of the 200Á Silver and Copper coated coir fiber with time

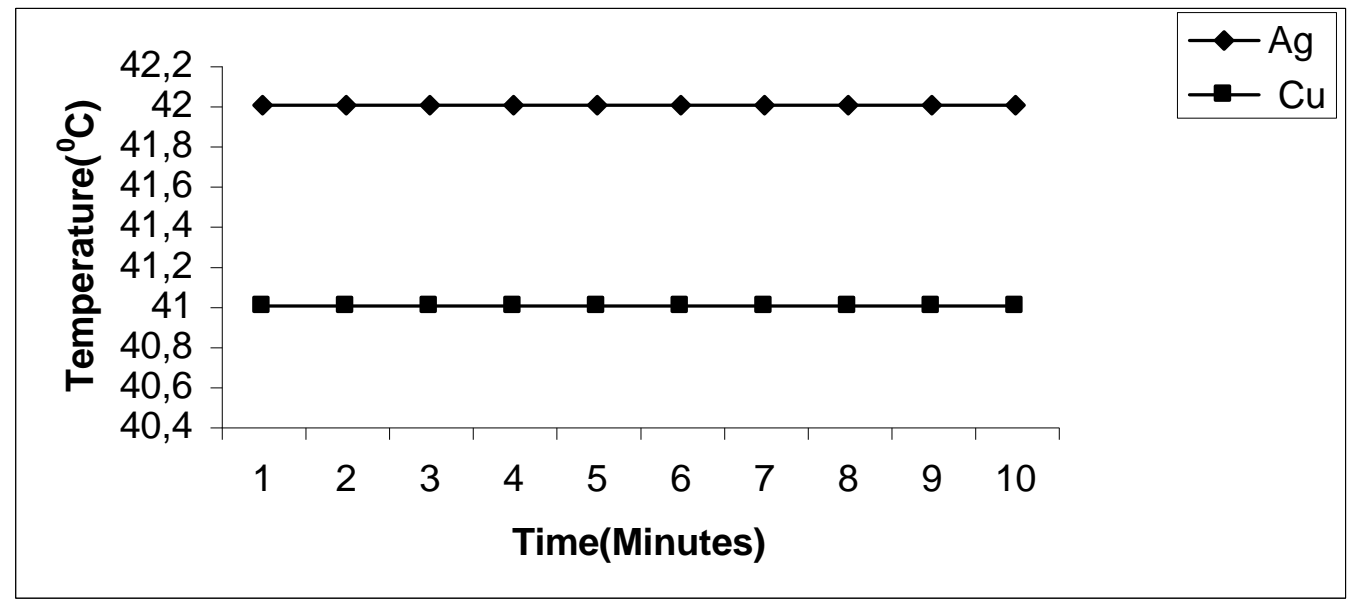

change from brown to black and flexibility also found to reduce. It is found that, at $150^{\circ} \mathrm{C}$ fiber becomes hard and beyond this temperature it is found to be brittle. Flexibility up to $80^{\circ} \mathrm{C}$ is sufficient for application in textile industry.

The present work demonstrates the potential of using coir fiber in smart textile applications. Coating of coir fiber with metals such as Silver, Copper and Aluminium at various thicknesses, provide a versatile combination of physical, electrical and optical properties for a variety of demanding applications. Coir fiber surface can be made conducting by coating it with metals in thin films. When current is allowed to flow through the coated side an equivalent heat is generated. Coir fiber is attractive because it is light weight, durable, flexible and cost competitive. It is possible to crimp and solder or subject to textile processing without any problem. This may also find use as camouflage materials that are of great importance to protect men and materials from enemies.

\section{Conclusions}

Metal coated coir fiber is produced by vacuum deposition of Silver, Copper and Aluminium. Thin film coated coir fiber conducts electricity and provides heat on application of mild potential. Irrespective of the nature of the metal, all the metal coated coir fibers produce heating effect on application of potential. Coating thickness of $200 \AA \AA, 500 \AA ̊$ and $1000 \AA \AA$ is used in the present study. Temperature rise on application of electric potential is found to be maximum for coir fiber with coating thickness of $200 \AA \hat{\text { sh }}$ showing that minimum use of metal provides enough temperature for the fabric. The rise in temperature is found to decrease with thickness of the coating. Preliminary study demonstrates the feasibility of using abundantly available cheap coir fiber in the development of thermo regulated textiles for outdoor wearing in winter. Compared to the synthetic polymers and phase change material, coir remains attractive because it exists as fiber in nature and is biodegradable and ecofriendly causing no environmental problems.

\section{Acknowledgement}

Thanks are due to the Board of Research in Nuclear Sciences, India (BRNS) for financial assistance, for carrying out this research in School of Technology and Applied Sciences, Mahatma Gandhi University and Central Coir Research Institute.

\section{References}

Barber C.R., 1955, A Platinum Resistance Thermometer for use at Low Temperatures, J. Sci. Instrum. 32(11): 416. 
Bledzki A. K and Gassan J., 1999, Composites Reinforced with Cellulose Based Fibers, Prog. Polm Sci. 24(2): 221.

Cho D., Lee S. G., W Park. H., Han S. O., 2001, Ecofriendly Biocomposite Materials Using Biofibers, Polm Sci. Tech. 13(4):460.

Czajka R., 2005, State of Art in Smart Textiles and Interactive Fabrics, Fibers and Textiles in Eastern Europe. 13(1): 13-15.

Dietzel Y., Przyborowski W., Nocke G., Offermann P., Hollstein F., Meinhardt J., 2000, Investigation on PVD Arc Coating on Polyamide Fabrics, Surface \& Coating Technology, 135 (1), 75-81.

Joffe R., Andersons J., L Wallstrom., 2003, Strength and Adhesion Characteristics of Elementary Flax Fibers with Different Surface Treatments, Composites. A 34(7): 603.

Komarov F. F., Pilko V. V., Yakushev V. A., Tishkov V. S., 1994, Super Hard Cubic BN
Layer Formation by Nitrogen IonImplantation, Nucl. Instr. and Meth. B 94(3):237-239.

Levin Richard I., Rubin David S., 1994, Statistics for Management, 436-442, 5, Prentice-Hall, Inc., U. S. A.

Linti C., Horter H., Osterreicher P., et al., 2006, Sensory Baby Vests for the Monitoring of Infants, Int. Workshop on Wearable and Implantable Body Sensor Networks, Proceeding, 135-137.

Stern F., 1957, A Note on the Structure and Mechanical Properties of Coir Fiber $J$. Tex. Inst. Trans. 48(1): 21-25.

Yao X. Y., Fogas P. B., Brown I. G., Rubin M. D., 1993, Modification of the Optical Spectra of Glass by Metal Ion Implantation, Nucl. Instr. and Meth. B 80/81(Part2): 1171-1173. 